\title{
Grupo de Apoio Psicológico a Mulheres em Situação de Infertilidade
}

\author{
Ednéia Aparecida Peres Hayashi ${ }^{1}$ \\ ${ }^{1}$ Universidade Estadual de Londrina, PR, Brasil.
}

\author{
Josy de Souza Moriyama ${ }^{1}$ \\ ${ }^{1}$ Universidade Estadual de Londrina, PR, Brasil.
}

\begin{abstract}
Resumo: Este trabalhoteve como objetivo descreverum relato de experiênciaa partir deum Programa de Intervenção com mulheres em situação de infertilidade. Tal Programa faz parte do Projeto de Extensão da UEL/PR, na área da Psicologia, com fundamento na Análise do Comportamento. Foram realizados dois grupos, compostos por sete mulheres cada, de Londrina e região, entre 31 e 42 anos, em situação de infertilidade conjugal. Realizou-se 10 sessões, de aproximadamente duas horas cada, semanalmente. Após dois meses do término, realizou-se sessões de followup. Os procedimentos utilizados foram técnicas de dinâmica de grupo, técnicas da Análise do Comportamento, como modelagem e modelação, Terapia de Aceitação e Compromisso (ACT) e Psicoterapia Analítica funcional (FAP). Realizou-se avaliações qualitativas por meio de dados obtidos com os relatos das participantes. A partir da fala das participantes, puderam ser percebidas mudanças em seus comportamentos, tanto dentro das sessões quanto em seu ambiente natural, de acordo com seus relatos verbais. A intervenção grupal tem o potencial de promover a aprendizagem de um repertório de enfrentamento das dificuldades relacionadas à infertilidade, o fortalecimento de aspectos positivos no relacionamento conjugal e social, além da aceitação emocional e seu manejo. Durante as sessões de follow-up, quatro participantes relataram estar dando início ao processo de adoção e, cinco participantes conseguiram atingir a gravidez. Sugere-se a replicação deste Programa com este tipo de população, bem como estudos com controle de variáveis.
\end{abstract}

Palavras-chave: Infertilidade, Psicoterapia em Grupo, Terapia de Aceitação e Compromisso, Psicoterapia Analítica Funcional, Análise do Comportamento.

\section{Psychological Support Group for Women in Situation of Infertility}

\begin{abstract}
This study aimed to report a clinical intervention, based on the principles of Behavior Analysis, in two groups of women in infertility situation. This program is part of the Extension Project of UEL/PR, in the field of Psychology, based on Behavior Analysis. Each group assisted seven women, between 31 and 42 years, in situation of conjugal infertility. Eleven sessions were held, approximately two hours each, once a week. After two months of the end of the groups, follow-up sessions were realized to monitor the changes observed. The procedures were group dynamics, problem solving and decision making techniques, Social Skills Training, Acceptance and Commitment Therapy (ACT) and Functional Analytic Psychotherapy (FAP). To this end, it was sought to do Functional Analysis of the behaviors of each participant. Quantitative and qualitative evaluation, from data obtained with the session reports was realized. The group intervention led to the learning of a behavioral repertoire of coping with the difficulties related to infertility, the strengthening of positive aspects in the marital and social relationship, besides the emotional acceptance and its handling. During and after the follow-up sessions, four participants reported being starting the process of adoption and five participants were able to achieve pregnancy. It is suggested that further studies with wider control variables should be conducted to test the effectiveness of the procedures used.
\end{abstract}

Keywords: Infertility, Group Psychotherapy, Acceptance and Commitment Therapy, Functional Analytic Psychotherapy, Behavior Analysis. 


\title{
Grupo de Apoyo Psicológico a Mujeres en Situación de Infertilidad
}

\begin{abstract}
Resumen: El objetivo de este trabajo fue describir un relato de experiencia proveniente del programa de intervención con mujeres en situación de infertilidad. El programa forma parte de un Proyecto de Extensión, de la Universidad Estatal de Londrina (UEL), Provincia de Paraná, en el área de la Psicología, con base en el Análisis del Comportamiento. Se formaron dos grupos con siete mujeres, entre 31 y 42 años, en situación de infertilidad. Se llevaron a cabo 10 sesiones de aproximadamente dos horas semanales. Dos meses después del término, se realizaron sesiones de follow-up. Los procedimientos utilizados fueron técnicas de dinámica de grupo, técnicas de Análisis de Comportamiento tales como el modelado y modelado, Terapia de Aceptación y Compromiso (ACT) y Psicoterapia Analítica Funcional (FAP). Se realizaron evaluaciones cualitativas por medio de datos obtenidos con los relatos de las participantes. A partir del habla de las participantes, se pudieron percibir cambios en sus comportamientos, tanto dentro de las sesiones y en su ambiente natural, de acuerdo con sus relatos verbales. La intervención grupal tiene el potencial de promover el aprendizaje de un repertorio de enfrentamiento de las dificultades relacionadas a la infertilidad, el fortalecimiento de aspectos positivos en la relación conyugal y social, además de la aceptación emocional y su manejo. Durante las sesiones de follow up, cuatro participantes relataron que estaban dando inicio al proceso de adopción y cinco participantes lograron el embarazo. Se sugiere la replicación de este Programa con este tipo de población, así como estudios con control de variables.
\end{abstract}

Palabras clave: Infertilidad, Psicoterapia en Grupo, Terapia de Aceptación y Compromiso, Psicoterapia Analítica Funcional, Análisis del Comportamiento.

O projeto de parentalidade é um dos objetivos de muitos casais. Quando isso não se concretiza, pode haver consequências negativas, como sentimento de tristeza, de ansiedade, de frustração, bem como prejuízo nos relacionamentos conjugal, familiar e social.

Segundo Batista, Bretones e Almeida (2016), a infertilidade é considerada pela Sociedade Americana de Medicina Reprodutiva (ASRM) uma doença e um problema de saúde pública. Ela é definida pela incapacidade de conseguir uma gravidez bem-sucedida após 12 meses ou mais de relações sexuais sem o uso de medidas anticonceptivas.

A situação de infertilidade pode acontecer pela dificuldade de se atingir a gravidez ou de mantê-la, podendo ser classificada em três tipos: infertilidade primária, infertilidade secundária e infertilidade relativa. Na infertilidade primária, o casal não conseguiu atingir a concepção desde a primeira tentativa. $\mathrm{Na}$ infertilidade secundária, o casal já conseguiu levar pelo menos uma gravidez a termo, mas falhou nas tentativas seguintes. A infertilidade relativa ocorre quando, apesar de atingir a concepção, o casal não consegue levar a gravidez adiante (Delgado, 2007).

Segundo dados da Organização Mundial da Saúde (OMS) - como citado em Farinati, Rigoni e
Müller (2006) -, estima-se que entre 60 e 80 milhões de pessoas em todo o mundo, em algum momento de suas vidas, enfrentem dificuldades para concretizar seu projeto de paternidade ou maternidade. Calcula-se que esse índice atinja aproximadamente $15 \%$ dos casais em idade reprodutiva.

Fatores causais masculinos e femininos contribuem, de maneira isolada, com aproximadamente $35 \%$ das causas da infertilidade, sendo o restante atribuído a variáveis desconhecidas (10\%) ou à associação de causas masculinas e femininas $(20 \%$ a $30 \%)$. Atualmente, os profissionais que lidam com o quadro de infertilidade recomendam que, mesmo após ser detectado o fator causal apenas em um dos cônjuges, deve-se usar o termo casal infértil, no sentido de que ambos deverão seguir e participar juntos dos tratamentos.

Gorayeb, Borsari, Gomes, Romão e Shuhama (2009) apontam que, para os casais que planejam filhos, o diagnóstico de infertilidade pode levar a prejuízos na relação conjugal, na vida profissional e nas interações sociais. Montagnini, Blay, Novo, Freitas e Cedenho (2009) ressaltam que a infertilidade interrompe um projeto de vida pessoal e do casal, produzindo sofrimento para ambos. Ela é considerada para a maioria dos casais como o evento mais estressante de suas 
vidas. Estudos demonstram que homens e mulheres que buscam tratamento para infertilidade apresentam alto nível de estresse (Gradvohl, Osis \& Makuch, 2013).

Diante da complexidade das consequências geradas pela infertilidade na vida do casal, ressalta-se a importância do atendimento psicológico nessa situação específica. Uma das modalidades de atendimento diz respeito a intervenções em grupo, o qual pode funcionar como uma rede de apoio a seus membros. Zanini, Peixoto e Nakano (2018) defendem que a rede social é o grupo de pessoas com as quais o indivíduo mantém contato ou alguma forma de vínculo social e que podem ser fonte de apoio social. Este pode ser considerado como algo que diz respeito aos recursos postos à disposição por outras pessoas em situações de necessidade. Nesse sentido, as intervenções em grupo, como rede de apoio social, geralmente são bastante efetivas, por possibilitar a troca de experiências de pessoas que se encontram em situações semelhantes (Delitti \& Derdyk, 2008; Feitosa, Feitosa \& Oliveira, 2016). Tratando-se do tema infertilidade, na literatura há escassez de trabalhos envolvendo o atendimento grupal a essa população (corroborado por Cordeiro \& Gomes, 2013). Isso sugere a necessidade de trabalhos que relatem experiências dessa natureza.

Este trabalho consiste em um relato de experiência no qual serão descritos os procedimentos utilizados nas sessões de um programa de intervenção decorrente de um projeto de extensão da Universidade Estadual de Londrina (UEL), no Paraná, aplicado a dois grupos de mulheres em situação de infertilidade conjugal. Além disso, serão descritas verbalizações das participantes sobre algumas mudanças consideradas positivas quanto ao enfrentamento da situação de infertilidade. O objetivo dos grupos era promover a aceitação emocional em relação à situação de infertilidade, como os sentimentos de ansiedade e a retomada de atividades que as participantes estavam se esquivando (por exemplo, encontrar familiares que poderiam perguntar sobre quando o casal teria filhos). Como objetivo específico, buscou-se levantar e consolidar reforçadores potenciais nas relações conjugal, familiar e social.

\section{Método}

Trata-se de um estudo descritivo exploratório inicial, uma vez que, mediante a impossibilidade de manipulação e de controle das variáveis, foi feito um exercício de interpretação dos relatos das participantes.

\section{Participantes}

Participaram dos atendimentos um total de 14 mulheres, divididas em dois grupos (G1 e G2), na faixa etária entre 31 e 42 anos, da cidade de Londrina e região, com escolaridade entre ensino fundamental completo e ensino superior completo, faixa socioeconômica correspondente à classe média, em situação de infertilidade conjugal. Das participantes, 13 encontravam-se em situação de infertilidade primária (ausência de gravidez confirmada) e apenas uma participante (G1) apresentava infertilidade relativa (abortos repetitivos). As participantes foram nomeadas no presente relato como: P1, P2, P3, P4, P5, P6, P7 (Grupo 1) e P8, P9, P10, P11, P12, P13 e P14 (Grupo 2).

\section{Procedimento}

O recrutamento das participantes ocorreu por meio de divulgação na mídia. Como primeiro critério, as mulheres deveriam estar em situação de infertilidade conjugal, isto é, tentando engravidar sem êxito há no mínimo um ano, ter a idade mínima de 18 anos e residir em Londrina ou na região.

Depois da divulgação, deu-se início à fase de seleção das participantes, a qual consistiu em uma entrevista semiestruturada de triagem individual. Nessa entrevista, foram levantados os seguintes aspectos: dados pessoais; histórico da infertilidade, incluindo o início das tentativas para engravidar, o acompanhamento médico, os tratamentos, os exames e a medicação utilizada até o momento da entrevista; relacionamento familiar, conjugal e social, como a perda de interesse em atividades sociais em função da infertilidade; expectativas relacionadas à participação no grupo.

Vale ressaltar que, durante as entrevistas, algumas mulheres desistiram de participar devido a fatores como o horário dos atendimentos e a localização dos encontros. Outras apresentavam necessidades específicas para atendimento individual, as quais foram encaminhadas para serviço específico.

Após a seleção das participantes, iniciou-se o atendimento grupal. Cada grupo foi atendido em semestres distintos entre 2013 e 2014. Foram realizadas 10 sessões com cada grupo, com um encontro por semana, na Clínica Psicológica da Universidade Estadual de Londrina. As sessões foram elaboradas e programadas pelas docentes do Projeto, em fase anterior à sua execução. As sessões eram conduzidas por uma docente e uma estagiária do quinto ano do curso 
de Psicologia, enquanto três estagiárias do quarto ano ficavam presentes na sala e faziam o registro escrito dos encontros. As observações e o registro das estagiárias ocorreram com a finalidade de aprenderem a intervir sozinhas em grupos posteriores.

Os procedimentos utilizados com os dois grupos atendidos foram: técnicas de dinâmica de grupo; técnicas da Análise do Comportamento, como modelagem e modelação (Calais \& Bolsoni-Silva, 2008), Terapia de Aceitação e Compromisso (Hayes, 1987); Psicoterapia Analítica funcional (Kohlenberg \& Tsai, 2001). Dois meses após o término de cada grupo, foi realizada uma sessão de follow-up com o intuito de verificar a generalização e a manutenção das mudanças comportamentais ocorridas ao longo das sessões de intervenção. A seguir, será descrito o desenvolvimento das sessões, com seus objetivos e procedimentos.

\section{Descrição das sessões}

Sessão 1: o objetivo desta sessão foi conhecer as participantes, suas características pessoais, suas expectativas para si e para o grupo e apresentar os objetivos do grupo.

Descrição da sessão: inicialmente, realizou-se a apresentação das terapeutas, das estagiárias e dos objetivos do grupo. Em seguida, foi estabelecido o contrato terapêutico, a partir da leitura e assinatura do Termo de Consentimento Livre e Esclarecido. Por se tratar de um estudo decorrente de um projeto de extensão da Universidade, as autoras do trabalho foram instruídas pelo Comitê de Ética em Pesquisa da Instituição de que somente projetos de pesquisa poderiam ser cadastrados para a avaliação, por isso a aplicação apenas do Termo de Consentimento Livre e Esclarecido às participantes dos grupos.

Após a assinatura do Termo de Consentimento, deu-se início à primeira atividade, que constou da Técnica do Cosme e Damião: foi pedido que as participantes se juntassem em dupla e se apresentassem uma para a outra, falando de aspectos pessoais, como lazer, atividades que mais gostavam etc. Depois, uma apresentava a outra para o restante do grupo. O objetivo dessa técnica foi observar se as participantes falariam apenas sobre as dificuldades de engravidar ou se conseguiriam abordar outros assuntos.

De maneira geral, as participantes do grupo 1 (G1) descreveram dificuldades vivenciadas em relação à situação de infertilidade. A maioria contou sobre cobranças da família para engravidarem. A participante P1 disse que era filha única e que sua mãe a criou sozinha, então ela precisava lhe dar um neto. Chorou ao falar do dia das mães na igreja e da cobrança que fazia sobre si mesma. Ainda verbalizou: "não sinto mais tanta vontade e prazer em fazer sexo se não estiver no período fértil e vejo meu marido como uma máquina de fazer bebês".

As participantes do grupo 2 (G2), embora também tenham relatado algumas dificuldades relacionadas ao quadro de infertilidade, ressaltaram aspectos ligados ao trabalho, às suas habilidades e aos relacionamentos familiares. A participante P11 contou que teve algumas crises de pânico e que tinha muito medo de fazer a cirurgia de endometriose indicada por seu médico. Falou que se interessou pelo grupo porque gostaria de conversar sobre o assunto sem ter que ouvir as pessoas falarem que "é só tirar da cabeça que dá certo".

De modo geral, as participantes disseram que gostaram de poder falar com pessoas que entendiam os seus problemas e passaram pela mesma situação, pois se sentiam diferentes dos amigos que já tinham filhos. Contaram que se magoavam com comentários corriqueiros sobre o assunto, chegando a evitar algumas pessoas que pudessem fazer perguntas. Ao final, as terapeutas ressaltaram a importância do espaço do grupo para as participantes falarem e escutarem o que pensavam e sentiam, podendo cada uma ter o seu momento e, juntas, constituírem um grupo de apoio.

Sessão 2: os objetivos desta sessão foram promover a integração entre as participantes do grupo e propiciar a exposição de sentimentos e objetivos pessoais.

Descrição da sessão: no início, as terapeutas perguntaram como havia sido a semana das participantes e se elas haviam se lembrado sobre o que conversaram na semana anterior. A participante P1 comentou que estava feliz porque, um dia antes da presente sessão, teve uma relação sexual com o marido sem o objetivo exclusivo de engravidar e que havia sido muito bom. Ela relatou ainda que, no dia seguinte, seu esposo ligou para ela e disse que o dia anterior tinha sido maravilhoso. Ela, após essa atitude do marido, afirmou que mudou o corte de cabelo "para ficar mais bonita". As terapeutas e as participantes elogiaram a experiência que P1 teve com o marido e o relato feito ao grupo.

No grupo 2, a participante $\mathrm{P} 8$ contou que foi à casa de um parente, o qual estava evitando porque sempre a questionava se não teria filhos. Dessa vez, lembrou-se do grupo e respondeu que começaria um tratamento, e até contou o nome do médico, questionando-o se 
o conhecia. Em seguida, foi aplicada a "Técnica da Colagem", na qual são distribuídas revistas e cada participante faz uma colagem que a represente naquele momento, escrevendo seus objetivos pessoais.

As participantes do grupo 1 ressaltaram que um dos objetivos principais naquele momento de suas vidas era ter um filho. A participante $\mathrm{P} 5$ comentou que se sentia ansiosa, precisando ser "adubada", pois se sentia muito desanimada. Salientou que precisava se animar: "tenho que me animar, pois estou na corrida para realizar meu sonho, que é engravidar e constituir uma família”.

A participante $\mathrm{P} 2$ expôs sua colagem e comentou que um de seus objetivos era perseverar na "corrida contra o tempo" para cumprir seu maior sonho: o de gerar um filho e ter uma família linda e feliz. Ressaltou que, se fosse para ficar só o casal, que "o Senhor os consolasse e que isso nunca interferisse no relacionamento deles", avaliado por ela como "um lindo relacionamento".

A participante P7 apresentou sua colagem dizendo que ultimamente ela sentia muito medo do trânsito e que queria superá-lo, pois já fazia quase um ano que tal sentimento persistia. Ressaltou ainda que precisava "descansar", porque já fazia três anos que não tirava férias. Outro objetivo comentado foi o de ter um bebê, uma vez que desejava ser mãe e dar carinho a alguém. Por fim, outro objetivo relatado foi a necessidade de fazer dieta e exercícios físicos.

Para a participante P1, segundo seu relato, seus objetivos consistiam em: decorar a sua casa, ter um filho, voltar a ter união entre os irmãos, ter mais tempo de férias, emagrecer e praticar exercícios físicos.

No grupo 2, o objetivo de ter um filho também estava presente nas atividades de todas as participantes. A seguir, serão descritos os outros objetivos relatados por elas. A participante P8 explicou sua colagem dizendo que via a decisão de engravidar como uma viagem, um caminho a seguir, e que, para isso, seu esposo precisaria estar de mãos dadas com ela, seguindo o mesmo caminho. A terapeuta questionou a participante se eles estavam de mãos dadas naquele momento, e ela disse que muitas vezes não, pois ele acabava realizando outros projetos diferentes dos dela.

A participante P9 disse que estava muito estressada com problemas familiares e que havia parado de fazer várias coisas das quais gostava, por estar se sentindo muito desanimada. Seu objetivo era voltar a fazer tais atividades. A participante P14 disse que gostava muito de comer, mas que gostaria de se cuidar mais e emagrecer. A participante P12 explicou sua colagem - uma mulher grávida e famílias com filhos - dizendo que havia interrompido as investigações sobre a infertilidade por questões financeiras, mas que atualmente já poderia voltar a fazer os exames. No entanto, sentia muito medo de descobrir algum problema real. A terapeuta perguntou se um dos seus objetivos poderia ser tirar essa dúvida. Ela confirmou que sim.

A participante $\mathrm{P} 13$ explicou sua colagem dizendo que gostaria de cuidar mais de si e trabalhar menos, pois ainda morava com seus pais e distante de seu marido, o qual trabalhava em outra cidade. Contou que, inclusive, deixou de atuar na área em que gostaria para se dedicar ao negócio dos pais. A participante P11 colou a frase "levar a vida com mais leveza" e explicou que esse seria seu objetivo, visto que sentia sua vida "pesada" e gostaria de se preocupar menos com a opinião de outras pessoas. Também disse que queria continuar com os exames e os procedimentos para engravidar, pois sempre os interrompia por sentir muita ansiedade e medo. A participante P10 disse que sua vida era só trabalho, ficando muito em função das questões financeiras, e que isso pesava bastante para decidirem tentar outro processo de fertilização. Também gostaria de se cuidar mais, pois era ela quem sustentava a família de origem. Ao final da sessão, as terapeutas valorizaram o fato de as participantes colocarem os cuidados com elas mesmas entre a maioria de seus objetivos.

As integrantes do grupo relataram que gostaram de participar das reuniões e, principalmente, de rever seus objetivos porque, muitas vezes, ficavam pensando apenas em ter filhos, e não em outras áreas de suas vidas, como a profissional e o próprio relacionamento conjugal.

Sessão 3: esta sessão visou levar as participantes à auto-observação e ao fortalecimento de aspectos pessoais positivos, tais como: habilidades, qualidades e reforçadores potenciais.

Descrição da sessão: deu-se início à “Técnica da Flor", uma flor de papel foi entregue a cada uma, com as pétalas dobradas. A terapeuta pediu que abrissem as pétalas, escrevessem o seu nome no centro da flor e, em cada pétala, colocassem aspectos positivos de si. As participantes citaram qualidades como carinhosa, companheira, amiga. Quando cada uma lia suas qualidades e ainda faltavam pétalas para serem 
preenchidas, as demais participantes ressaltavam outras características, como bonita, alegre, comunicativa, entre outras. A participante P12 contou que havia marcado uma consulta com um dos médicos em comum de outras participantes para continuar as investigações e os exames, explicando que a última sessão a ajudou a tomar essa decisão.

Para finalizar o encontro, as terapeutas pediram às participantes que dissessem o que levariam consigo. Elas informaram que precisavam se valorizar mais e reservar mais tempo para cuidarem de si. Então, as terapeutas passaram como "tarefa de casa" se valorizar mais, olhar para aspectos positivos de si e também do companheiro e fazer algo para elas mesmas.

Sessão 4: teve como objetivos o conhecimento das dificuldades vivenciadas pelas participantes em relação às situações envolvendo a infertilidade, o levantamento do repertório de enfrentamento do casal e a promoção de informações científicas sobre a infertilidade conjugal.

Descrição da sessão: as terapeutas perguntaram a respeito da "tarefa de casa" (se valorizar, fazer algo para si e elogiar o companheiro). As participantes relataram ter colocado a flor com as qualidades em lugares estratégicos para se lembrarem de olhar o que possuíam de bom. Relataram que os maridos gostaram de também receber elogios. A participante P1 comentou que passou batom e o marido disse que ela estava mais bonita. A terapeuta perguntou o que ela fez após esse comentário. P1 respondeu que o agradeceu e disse-lhe que se sentia feliz quando ele a elogiava.

Em seguida, deu-se início à atividade central, que englobou a seguinte tarefa: em duplas, as participantes deveriam conversar e escrever sobre as frases: "Quais as dificuldades que o casal enfrenta quando tenta engravidar e não consegue? Como eles podem lidar com isso?". As participantes falaram de suas próprias experiências e do quanto era importante o casal estar unido para enfrentar as dificuldades, especialmente as cobranças das pessoas. Também falaram que o relacionamento conjugal às vezes ficava abalado.

Após a discussão e a finalização da atividade, foi entregue a cada participante uma folha contendo informações científicas sobre a reprodução humana e a infertilidade. Como "tarefa de casa", foi solicitado às integrantes que levassem a folha para casa e a lessem com seus companheiros.

Sessão 5: este encontro buscou levar as participantes a discutirem informações científicas a res- peito da reprodução e da infertilidade. Outra finalidade de tal sessão foi promover o fortalecimento de momentos do casal (reforçadores para o casal) e o autoconhecimento das participantes quanto aos sentimentos sobre si e sua sexualidade, visando à aprendizagem de novos comportamentos e/ou ao fortalecimento de repertório.

Descrição da sessão: as terapeutas iniciaram a sessão indagando às participantes como tinha sido a semana delas. A participante P7 disse que foi viajar e que foi dirigindo. A terapeuta verbalizou que esse enfrentamento foi muito importante e ressaltou dizendo que, embora ela tivesse medo de dirigir, não deixou de fazê-lo. Quanto à "tarefa de casa" (leitura do material com o companheiro), algumas relataram que leram com seu companheiro, porém a maioria afirmou que leu sozinha.

As terapeutas iniciaram a técnica principal solicitando a leitura de um texto relativo à mulher, que discutia como a sexualidade e a sensualidade iam muito além do ato sexual em si. O texto foi lido e discutido. Na discussão, as terapeutas explicitaram o significado de sexualidade, que incluía o prazer de dar um beijo, um toque, uma palavra que levasse ao prazer.

No grupo 1, a participante P5 disse que precisava melhorar a intimidade com o marido, que sabia que era uma dificuldade sua e que eles conversavam sobre isso. A participante $\mathrm{P} 7$ comentou que seu esposo dizia gostar muito dos momentos de intimidade do casal, como as carícias e as conversas, algumas vezes até mais que o ato sexual. Acrescentou que estava "se desligando da neura de ter um filho" e que estava cuidando mais de si, comprando roupa nova e fazendo tratamento para varizes. A participante $\mathrm{P} 1$ relatou que deixou para seu marido um "recadinho" com batom no espelho do banheiro e que, no dia seguinte, ele fez a mesma coisa.

No grupo 2, algumas participantes contaram como estavam insatisfeitas sexualmente. Umas disseram que passaram a ver o sexo apenas com a função de engravidar, outras, que não se sentiam no direito de tomar a iniciativa com os maridos. A participante P10 disse que não sentia mais atração pelo marido como antigamente, pois estava sempre cansada e sua tensão pré-menstrual (TPM) durava muito tempo. Foi discutido que o prazer está muito mais na "cabeça" que no corpo e, por isso, os hormônios não poderiam interferir tanto assim. Aquelas participantes que disseram estar satisfeitas sexualmente deram dicas de 
como melhorar o relacionamento sexual, de como a mulher poderia tomar a iniciativa, entre outras.

Como "tarefa", foi pedido a elas que "vivenciassem sua sexualidade durante a semana, que aumentassem a frequência do namoro com seu parceiro e que observassem o que sentiam nessas situações".

Sessão 6: os objetivos desta sessão foram levar as participantes à auto-observação de sensações corporais, como tensão-relaxamento, evocar sentimentos relacionados à ansiedade, ressaltar a importância da identificação de sentimentos e de sua vivência no momento em que ocorressem, sem tentar controlá-los.

Descrição da sessão: o início se deu com a indagação das terapeutas sobre a "tarefa de casa" (vivência da sexualidade). Algumas participantes contaram que namoraram e que curtiram esse momento com o marido, sem pensar em engravidar. Duas participantes (P4 e P2) disseram que foram ao cinema com o esposo, o que não acontecia há tempo, e que gostaram bastante. No grupo 2, as participantes P8 e P9 relataram também terem ido ao cinema com os companheiros. A participante P10 afirmou que procurou namorar o marido mesmo se sentindo cansada e que, depois de começar, havia sido muito bom. P12 contou que fez um exame o qual já deveria ter feito há um ano e não sentiu quase nenhuma dor. Ela disse ainda que tinha marcado mais três exames. A terapeuta e as participantes elogiaram-na.

Em seguida, aplicou-se a Técnica de relaxamento e evocação de ansiedade (Stevens, 1988). As terapeutas discutiram sobre o fato de não ser possível controlar sentimentos e pensamentos nem fugir deles. Foi discutido que o ideal seria aceitá-los como parte das situações vividas, pois aqueles seriam produtos destas. Desse modo, ressaltou-se a importância de se viver o momento presente em vez de ficar sob o controle do que ainda não aconteceu.

Como atividade complementar para as integrantes, as terapeutas desenvolveram a técnica para vivenciar o aqui e agora - adaptada de Hayes (1987) por Chagas, Guilherme e Moriyama, (2013). Uma das terapeutas pediu a cada uma delas que pegasse um chocolate "Bis". Após a última participante pegar o chocolate, a terapeuta comentou sobre o que elas fizeram com o chocolate no momento em que o pegaram. A maioria delas o havia comido. Então, a terapeuta distribuiu novamente um chocolate e solicitou que só o abrissem quando ela desse a ordem. Deu a instrução para abrir lentamente o papel do chocolate, olhar para ele, sentir seu cheiro e comê-lo lentamente, observando todas as sensações que esse ato proporcionava.

No grupo 2, a maioria das participantes (P8, P9, P10, P11, P13 e P14) contou ter passado por crises de ansiedade ao longo de suas vidas. Elas discutiram bastante o fato de se sentirem cobradas. P8 disse: "somos criadas para sermos perfeitinhas".

Foi pedido, ao final, que vivenciassem o momento presente durante a semana, como "tarefa de casa", lembrando que a relação sexual também deveria ser vivenciada dessa maneira.

Sessão 7: buscou-se neste encontro levar as participantes a identificarem e a vivenciarem seus sentimentos, promovendo o autoconhecimento.

Descrição da sessão: ela foi iniciada com a retomada da "tarefa de casa". Algumas participantes contaram que deram início a atividades físicas. As participantes P5 e P7 comentaram que estavam, inclusive, fazendo caminhadas juntas. A participante P3 contou que ela e o marido saíram para um bar e depois namoraram, finalizando: "foi muito bom namorar". No grupo 2, a participante P8 contou que conseguiu tocar piano durante a semana. A participante P11 contou que não chegou a realizar alguma atividade que gostasse em especial, mas tentou exercitar o que aprendeu: "aproveitar a vida em suas atividades rotineiras".

Após as discussões, foi iniciada a Técnica "Identificação com a Roseira” (Stevens, 1988), com autorretrato da roseira, ao final. Essa técnica tem como objetivo promover a auto-observação e o autoconhecimento. Foi colocada uma música para relaxamento e pedido para as participantes fecharem os olhos e começarem a imaginar que eram uma roseira. A condutora da atividade foi pedindo para imaginarem que tipo de roseira cada uma seria e como era o ambiente em torno delas, entre outros detalhes.

Na discussão da Técnica, as integrantes do grupo 1 relataram, de modo geral, que antes de participarem do grupo se sentiam sozinhas, tristes, e depois passaram a se sentir mais fortes. Disseram que se permitiam vivenciar outras coisas em sua vida, e não apenas focar em "ter um bebê", como ilustra a verbalização de P7: "eu e meu marido estamos nos programando para viajar, para pensar e fazer outras coisas", e o comentário de $\mathrm{P}$ 4: "o grupo está me ajudando, está sendo muito bom. Mudei meu foco. Quando fazia tratamento, só fazia isso. Agora estou até fazendo aula de muscula- 
ção". As terapeutas comentaram que estavam felizes com essas mudanças na vida das participantes. Uma das terapeutas comentou: "não podemos garantir que saiam daqui grávidas, mas queremos que saiam daqui fortalecidas". As participantes ainda comentaram que estavam lidando de maneira diferente quando inseridas em alguma situação envolvendo bebês ou grávidas, como pode-se perceber por P1, a qual comentou que, agora, no seu trabalho, conseguia dar parabéns ao encontrar uma cliente grávida.

No grupo 2, ao falarem de suas rosas, as participantes focaram bastante no modo como se relacionavam com o mundo, cuidavam dos outros e se deixavam cuidar. A participante P12 informou, a partir de seu desenho, que naquele momento, ao contrário de antes, não tinha mais medo dos resultados dos exames. Em seu desenho, uma mão estava segurando a rosa. Com isso, ela explicou que se sentia cuidada.

Sessão 8: teve como objetivo a promoção do autoconhecimento, do levantamento e fortalecimento de reforçadores potenciais e do planejamento para mudanças por parte das integrantes.

Descrição da sessão: ela iniciou-se com a aplicação da Técnica Gosto/faço, Gosto/não faço, Não gosto/faço e Não gosto/não faço. Essa técnica consistiu em pedir às participantes que escrevessem, em quatro quadrantes, o que gostavam e faziam, o que não gostavam e não faziam, o que não gostavam, mas faziam e o que gostavam, mas não faziam. As participantes do grupo 1 disseram que gostavam de atividades como ler, viajar, ir ao cinema, porém não estavam conseguindo fazê-las ultimamente. As terapeutas perguntaram como elas poderiam transformar o "gosto e não faço" em "gosto e faço". A participante P7 comentou que já estava planejando com o marido uma viagem. A participante $\mathrm{P} 4$ disse que iria aumentar as idas ao cinema com seu marido.

Sessão 9: aqui, o objetivo era levar as participantes a desmistificarem "regras sociais" que controlavam seus comportamentos e permitir a reformulação e a formulação de novas regras.

Descrição da sessão: foi dado início à Técnica Concordo/Discordo", referente a frases relacionadas às regras sociais. Foi solicitado que, em duplas, fosse feita uma discussão sobre algumas frases, colocando "concordo" ou "discordo" para cada uma. Nesse momento, devido à peculiaridade de cada grupo, foram desenvolvidas frases distintas, com objetivos específicos a serem discutidos.
Para o grupo 1, as frases discutidas foram: "O casal só pode ser considerado uma família se tiver filho(s)"; “Toda mulher tem que ser mãe"; "O verbo 'gerar' significa gerar filho(s)"; "Só posso ser feliz se for mãe”. As frases discutidas no grupo 2 foram além da questão da maternidade, porque as participantes apresentavam outras preocupações e problemas de relacionamento. As frases foram: "O verbo 'gerar' significa gerar filho(s)"; "Sempre tenho que me preocupar ou considerar a opinião que as outras pessoas terão de mim”; "O casal só pode ser considerado uma família se tiver filho(s)" e, por fim, "Para relação sexual, sempre o homem deve ter a iniciativa".

As participantes apresentaram diferenças quanto à opinião sobre algumas frases, mas foram unânimes em dizer que o verbo "gerar", embora estivesse relacionado pela sociedade à gravidez, significava muito mais do que isso, como ilustrou a fala de P1: "a mulher pode gerar outras coisas, como gerar amizades". Ainda, em relação à frase "O casal só pode ser considerado uma família se tiver filho(s)", algumas participantes comentaram que antes pensavam assim, mas que agora estavam se considerando uma família somente com o marido.

Sessão 10: o objetivo desta sessão foi levar as participantes a fazerem uma exposição de si, uma avaliação de sentimentos e de objetivos pessoais pós-intervenção.

Descrição da sessão: foi desenvolvida a “Técnica da Colagem" (idêntica à descrita na Sessão 2). As integrantes relataram que participar do grupo foi muito importante, pois agora não se sentiam mais sozinhas e puderam ver que havia outras pessoas passando por situações semelhantes. A participante P5 verbalizou que estava se sentindo feliz por ter se unido ao grupo, aprendendo a lidar de forma diferente com as situações da sua vida. Ela comentou que "uma amiga falou que está grávida, mas não me senti mal, antes me sentia mal com esse tipo de notícia”. A participante P1 disse: "este bebê aqui quer dizer que eu estou cheia de amor pra dar; essa flor quer dizer que estou me sentindo bonita; essa ave, que me sinto livre; e essa moça bonita aqui quer dizer que eu estou me sentindo sexy". A participante $\mathrm{P} 4$ informou que ela e o marido mudaram os planos e que agora iriam entrar na fila para adoção. As terapeutas perguntaram sobre como estavam se sentindo e $\mathrm{P} 4$ afirmou estarem se sentindo felizes e que a decisão havia sido conjunta. A participante P7 verbalizou: "esse casal aqui representa eu e meu 
marido, pois estamos em harmonia, em um momento muito bom; essa modelo aqui quer dizer que eu estou me sentindo linda e poderosa e essa família é que eu vou continuar tentando ter filhos, é claro, é meu sonho, mas não é mais o meu foco, como antes".

O grupo 2 começou com a terapeuta questionando se as participantes haviam feito as tarefas combinadas. A P13 contou que saiu com amigos que não via fazia tempo. P10 relatou que estava conseguindo desligar o computador às $20 \mathrm{~h}$, parando de trabalhar, de forma a aproveitar mais o tempo com as pessoas. A participante P12 falou que saíram os resultados de seus exames: estava com miomas nos ovários e suas trompas, obstruídas. A notícia a deixou bastante triste, pois o médico lhe disse que ela precisaria fazer a fertilização. As participantes e a terapeuta buscaram apoiá-la.

Após realizarem as novas colagens, foi pedido às participantes que comentassem e comparassem com a colagem feita na segunda sessão. A participante P10 se surpreendeu ao ver que na primeira colagem a maior figura era de um computador e que agora ela não havia colocado nada que se referisse ao trabalho. Também se surpreendeu ao perceber que na primeira vez não havia colocado o marido, e nesta última, sim. Comentou também que o relacionamento entre os dois estava bem melhor, contando detalhes de que agora tinha mais paciência para ouvi-lo falar de assuntos banais e que o relacionamento sexual deles havia aumentado em frequência, pois ela voltou a sentir desejo pelo marido. Ela relatou que, apesar de colocar a foto de uma gestante, sua prioridade era "aproveitar a vida e ser feliz no agora".

P12 explicou sua atividade dizendo que havia colocado um casal de velhos abraçados e sorrindo porque, com o novo diagnóstico, sabia da possibilidade de acabar ficando apenas ela e o marido, mas gostaria que ficassem bem. Porém atrás da folha colou a figura de uma gestante, dizendo que ainda esperava conseguir engravidar naturalmente. A participante P8 colocou em sua atividade várias frases, finalizando com uma: "e daí?", fala bastante repetida ao longo das sessões, em relação à preocupação com o que os outros pensavam. Ela explicou que o grupo foi muito importante para ela se sentir respeitada e segura em falar o que sentia, pois sempre teve muito receio do que os outros pensariam dela, pelo medo de errar e pela necessidade de agradar a todos. Contou que, diferentemente da primeira atividade, ela e o marido, durante sua participação no grupo, foram se aproximando, conversando mais e agora estavam olhando para o mesmo caminho.

A participante P9 contou que no início do projeto tinha medo de fazer um exame, mas que finalmente tinha conseguido marcá-lo, devido aos relatos das demais participantes. Falou que no primeiro momento no grupo estava com dificuldades financeiras e emocionais, e agora já estava se recuperando, tanto financeiramente quanto emocionalmente. Além disso, tinha voltando a fazer atividades das quais gostava. P14 confidenciou que estava fazendo regime, comendo menos, e estava se sentindo melhor, porque não ficava muito "cheia". Relatou ainda que havia emagrecido três quilos em um mês. P11 contou que andava estressada por estar chegando a data de fazer os exames para a cirurgia de endometriose que precisava realizar, mas que dessa vez estava disposta a não abandonar o tratamento.

As terapeutas discutiram com o grupo que, apesar de o medo ser incontrolável, era possível enfrentar a situação, fazer os exames e os procedimentos. P13 mostrou que em seu desenho atual os pais não estavam mais presentes como no primeiro. Ela dispensou um compromisso em família por causa do marido, colocando limites em seus pais e indo em busca de seus objetivos.

\section{Sessões de Follow-up}

Descrição da sessão: após dois meses da última sessão, foi realizado um encontro de seguimento com cada grupo atendido. Nele, aplicou-se a Técnica da Colagem, como descrita anteriormente (Sessão 2). No grupo 1, as participantes comentaram que antes tinham como único objetivo "engravidar a qualquer custo e buscar ajuda com o grupo". Uma das participantes (P1) relatou o seguinte: "Estava sem rumo, parecia que poderia ser feliz somente se gerasse um filho". A participante P7 explicitou: "estou cuidando mais de mim, em todos os sentidos, e não só o corpo. O grupo ajudou, pois nos dias atuais, quando tenho uma recaída, lembro do que aprendi". A participante P2 verbalizou que se sentia correndo atrás de seus sonhos e de seus objetivos e que estava se dedicando à sua carreira. A participante $\mathrm{P} 1$ disse que se sentia forte, cuidando da alimentação e fazendo caminhada. Disse que o grupo foi importante porque era um momento que ela precisava e, quando ficava mal, lembrava-se do que aprendeu nos encontros. As participantes P1, 
P7 e P5 comentaram que decidiram, junto a seus respectivos maridos, iniciar o processo de adoção. As terapeutas valorizaram tal decisão e se colocaram à disposição, caso fosse preciso. A participante P4 não pôde comparecer, pois estava em um curso sobre adoção, cuja presença era obrigatória.

No início da sessão de follow-up do grupo 2, as participantes ficaram trocando informações sobre os procedimentos médicos. P8 descobriu, por meio dos últimos exames, que possuía alguns pólipos os quais a impediam de engravidar. P11 relatou o sucesso de sua cirurgia de endometriose, na qual ficou tranquila e enfrentou a situação até o fim. P12 revelou que uma nova médica lhe explicou que suas trompas estavam obstruídas porque ela estava com uma infecção, cujo tratamento seria por meio de antibióticos. P13 comentou sobre a possibilidade de ir morar com o marido. Ao relatar a sua colagem, P11 mostrou a foto de uma criança, explicando que não era pela questão da infertilidade, mas porque a imagem lhe passava uma ideia de tranquilidade, e agora ela estava se sentindo mais calma. Falou que o grupo a ajudou bastante a tomar a decisão de fazer a cirurgia, a ter força e coragem para encarar o desafio. P13 comentou que P11 dava-lhe força para continuar, que o fato de todas elas estarem fazendo alguma coisa a incentivava a também fazer algo. P12 falou que concordava com P13, pois quando viu que a P11 tinha marcado a cirurgia, ela pensou: "se ela marcou, então eu também tenho que marcar a minha". Falou que a nova médica lhe disse que poderia acontecer uma gravidez natural agora que ela havia tratado a infecção, pois a obstrução poderia ter se curado.

Após alguns meses desses encontros, as participantes P1, P2, P11, P12 e P13 entraram em contato com as terapeutas para contarem que estavam grávidas.

\section{Resultados e discussão}

Os resultados descritos a seguir referem-se à análise das verbalizações das participantes ao longo das sessões do grupo.

Na primeira sessão, foi possível perceber as dificuldades das participantes diante das cobranças sociais e familiares sobre o casal para terem um filho, conforme apontam Gorayeb et al. (2009). A maioria delas vinha se esquivando de situações e de pessoas que pudessem fazer perguntas ou comentários aversivos a respeito de uma possível gravidez.

De forma geral, notou-se também, pelos relatos das participantes, que havia um excesso de atividades laborais e de responsabilidades, com poucos momentos de lazer.

Segundo Delgado (2007), a perda de interesse em situações sociais e o isolamento são bastante comuns entre casais inférteis. Para Hayes (1987), a esquiva de situações que geram sentimentos aversivos, como ansiedade e tristeza, por exemplo, apesar de promover um alívio momentâneo, impede que a pessoa entre em contato com reforçadores e venha a ter sentimentos de prazer. Assim, ao evitarem perguntas e a presença de crianças e de mulheres grávidas, as participantes também não entravam em contato com atividades, amigos e familiares que poderiam levá-las a se sentir bem e mesmo apoiá-las diante desse problema.

O estudo de Cunha, Carvalho, Alburquerque, Ludermir e Novaes (2008) sobre a associação entre infertilidade, Transtornos Mentais Comuns (TMC), (como ansiedade e depressão) e o apoio social, revelou a importância do apoio social para diminuir o estigma e os sentimentos negativos diante do diagnóstico da infertilidade. Neste estudo, houve a prevalência de TMC mais elevada entre as participantes que afirmaram ter tido modificação do relacionamento social, a partir do diagnóstico de infertilidade (deixando de sair por exemplo), do que entre as que negaram.

As sessões em grupo provavelmente representaram um espaço em que as participantes se sentiram seguras para falarem de seus sentimentos e de seus pensamentos aversivos em relação ao problema da infertilidade. Esse resultado vai ao encontro da citação de Delitti e Derdyk (2008) e de Feitosa et al. (2016) sobre a efetividade dos atendimentos em grupo, devido à troca de experiências entre pessoas com vivências semelhantes.

Logo após a primeira sessão, algumas participantes relataram algumas mudanças em relação às frequentes esquivas que vinham apresentando, por exemplo, visitando parentes que estavam evitando e respondendo às suas perguntas com naturalidade. Um exemplo do enfrentamento de situações bastante expressivo foi o de algumas participantes que haviam parado de realizar os exames, justificando ter medo de descobrir os motivos de não estarem conseguindo engravidar, e que depois os marcaram para dar continuidade à investigação.

É provável que, por meio da troca de experiências, as participantes puderam servir de modelo uma para a outra na busca pelo tratamento e no enfrentamento 
da situação de infertilidade. Os princípios da Terapia de Aceitação e Compromisso (ACT), de Hayes (1987), foram usados nas intervenções, buscando incentivá-las a aceitarem seus sentimentos e, apesar deles, voltarem a se expor a situações que estavam se esquivando. Muitos dos comportamentos que em ambiente natural estavam sendo evitados pelo risco de serem punidos (como, por exemplo, falarem de seus sentimentos em relação à dificuldade de engravidar e chorarem, ao falar sobre este assunto), foram valorizados e reforçados nas sessões, seja pelas terapeutas, seja pelas outras participantes, modelando comportamentos de enfrentamento, conforme preconiza a Terapia Analítica Funcional (FAP), de Kohlenberg e Tsai, (2001).

No início, algumas participantes relataram estar com problemas em seu relacionamento conjugal. Isso vai ao encontro das informações dos autores Gradvohl et al. (2013) de que a infertilidade traz problemas conjugais. Entretanto, notou-se que, ao longo dos encontros, muitas participantes relataram melhoras quanto à comunicação com os companheiros e à qualidade $\mathrm{e}$ à frequência das relações sexuais.

Outros resultados apresentados no decorrer das sessões foram mudanças e enfrentamentos em outras áreas da vida por algumas participantes, como parar de trabalhar após determinado horário, priorizando suas relações e seu casamento. Várias delas começaram a se exercitar e a cuidar mais da alimentação, da saúde e da aparência como um todo. Além disso, houve um aumento na prática de atividades de lazer com o parceiro e com amigos. Dessa maneira, supõe-se que o grupo tenha contribuído para aumentar a autoestima das participantes.

Por fim, destaca-se que os grupos provavelmente tenham o potencial de servir como uma rede de apoio entre as participantes, que se estendeu para fora das paredes da clínica, tanto durante os encontros quanto após seu término. Essa continuidade do contato entre as integrantes certamente é um dos maiores objetivos de um grupo desse tipo, uma vez que representa a continuidade de uma rede de apoio tão importante, como citam autores como Gorayeb et al. (2009); Moreira, Melo, Tomaz, \& Azevedo (2006); Zanini et al. (2018). Um grande resultado a ser ressaltado também foi a tomada de decisão de darem início ao processo de adoção, começado por uma das participantes e cogitado por mais três delas, todas do mesmo grupo.

Por se tratar de um projeto de extensão no qual buscou-se priorizar a prática e o atendimento à comunidade, não foi possível o controle das variáveis para se comprovar a efetividade do tratamento. Com base nas verbalizações das participantes, pode-se apenas inferir que as intervenções foram eficazes. Sugere-se que esse programa de intervenção seja replicado não apenas com esse tipo de população, mas também com homens em situação de infertilidade. Além disso, seria interessante estudos semelhantes com maior controle de variáveis.

\section{Referências}

Batista, L. A. T., Bretones, W. H. D., \& Almeida, R. J. (2016). O impacto da infertilidade: Narrativas de mulheres com sucessivas negativas pelo tratamento de reprodução assistida. Reprodução \& Climatério, 31(3), 121-127. https:// doi.org/10.1016/j.recli.2016.05.004

Calais, S. L., \& Bolsoni-Silva, A. T. (2008). Alcance e limites das técnicas comportamentais: Algumas considerações. In: M. R. Cavalcante (Org.), Análise do comportamento: Avaliação e intervenção. São Paulo, SP: Roca.

Chagas, M. T., Guilherme, G., \& Moriyama, J. S. (2013). Intervenção clínica em grupo baseada na terapia de aceitação e compromisso: Manejo da ansiedade. Acta Comportamentalia, 21(4), 495-508.

Cordeiro, M. S., \& Gomes, J. C. (2013). Ansiedade e relacionamento conjugal em mulheres com infertilidade: Impacto da terapia de grupo. Revista Portuguesa de Enfermagem de Saúde Mental, (9), 7-13.

Cunha, M. C. V., Carvalho, J. A., Albuquerque, R. M., Ludermir, A. B., \& Novaes, M. (2008). Infertilidade: Associação com transtornos mentais comuns e a importância do apoio social. Revista de Psiquiatria do Rio Grande do Sul, 30(3), 201-210. https://doi.org/10.1590/S0101-81082008000400009

Delgado, M. J. C. (2007). O desejo de ter um filho: As vivências do casal infértil (Dissertação de Mestrado). Universidade Aberta-Lisboa, Lisboa, Portugal.

Delitti, M., \& Derdyk, P. (2008). Terapia analítico comportamental em grupo. Santo André, SP: ESETec.

Farinati, D. M., Rigoni, M. S., \& Müller, M. C. (2006). Infertilidade: Um novo campo da psicologia da saúde. Estudos de Psicologia, 23(4), 433-439. https://doi.org/10.1590/S0103-166X2006000400011 
Psicologia: Ciência e Profissão 2019, 39, e179820, 1-13.

Feitosa, J. K. C., Feitosa, A. N. C., \& Oliveira, A. M. (2016). Psicoterapia analítico-comportamental em grupo. Id on Line Revista Multidisciplinare de Psicologia, 10 (31 supl. 2), 224-235. https://doi.org/10.14295/idonline.v10i31.539

Gorayeb, R., Borsari, A., Gomes, A. C. R., Romão, A. P., \& Shuhama, R. (2009). Caracterização clínica e psicossocial da clientela de um ambulatório de esterilidade. Estudos de Psicologia, 26(3), 287-296. https://doi.org/10.1590/ S0103-166X2009000300002

Gradvohl, S. M. O., Osis, M. J. D., \& Makuch, M. Y. (2013). Estresse de homens e mulheres que buscam tratamento para infertilidade. Revista Brasileira de Ginecologia e Obstetrícia, 35(6):255-61. https://doi.org/10.1590/S010072032013000600004

Hayes, S. C. (1987). A contextual approach to therapeutic change. In: N. Jacobson (Ed.), Psychotherapists in clinical practice: Cognitive and behavioral perspectives (pp. 327-387). (A. C. B. Barcellos, \& V. B. Haydu, Trad.). New York, NY: Guilford.

Kohlenberg, R. J., \& Tsai, M. (2001). Psicoterapia analítica funcional: Criando relações terapêuticas intensas e curativas. Santo André, SP: ESETec.

Montagnini, H. M. L., Blay, S. L., Novo, N. F., Freitas, V., \& Cedenho, A. P. (2009). Estados emocionais de casais submetidos à fertilização in vitro. Estudos de Psicologia, 26(4), 475-481. https://doi.org/10.1590/S0103166X2009000400008

Moreira, S. N. T., Melo, C. O., Tomaz, G., \& Azevedo, G. D. (2006). Estresse e ansiedade em mulheres inférteis. Revista Brasileira de Ginecologia e Obstetrícia, 28(6), 358-364. https://doi.org/10.1590/S0100-72032006000600007

Stevens, J. O. (1988). Tornar-se presente. (12a ed.). São Paulo, SP: Summus.

Zanini, D. S., Peixoto, E. M., \& Nakano, T. C. (2018). Escala de apoio social (MOS-SSS): Proposta de normatização com referência nos itens. Temas em Psicologia, 26(1), 387-399. https://doi.org/10.9788/tp2018.1-15pt.

\section{Ednéia Aparecida Peres Hayashi}

Graduação em Psicologia pela UEL, Docente do Curso de Psicologia do Departamento de Psicologia Geral e Análise do Comportamento da Universidade Estadual de Londrina (UEL), Londrina - PR. Brasil.

E-mail: edneiahayashi@yahoo.com.br

(iD https://orcid.org/0000-0003-0673-8607

Josy de Souza Moriyama

Graduação em Psicologia pela UEL, Docente do Curso de Psicologia do Departamento de Psicologia Geral e Análise do Comportamento da Universidade Estadual de Londrina (UEL), Londrina - PR. Brasil.

E-mail: josyama@hotmail.com

(iD) https://orcid.org/0000-0002-0019-8358

Endereço para envio de correspondência:

Universidade Estadual de Londrina

Rodovia Celso Garcia Cid/PR445 Km 380/Campus Universitário

CEP: 86057-970/Londrina-Paraná

Departamento de Psicologia Geral e Análise do Comportamento - Centro de Ciências Biológicas.

Recebido 11/05/2017

Reformulado 28/08/2018

Aceito 10/09/2018

Received 05/11/2017

Reformulated $08 / 28 / 2018$

Approved 09/10/2018 
Recibido 11/05/2017

Reformulated 28/08/2018

Aceptado 10/09/2018

Como citar: Hayashi, E. A. P., \& Moriyama, J. S. (2019). Grupo de Apoio Psicológico a Mulheres em Situação de Infertilidade. Psicologia: Ciência e Profissão, 39, 1-13. https://doi.org/10.1590/1982-3703003179820

How to cite: Hayashi, E. A. P., \& Moriyama, J. S. (2019). Psychological Support Group for Women in Situation of Infertility. Psicologia: Ciência e Profissão, 39, 1-13. https:// doi.org/10.1590/1982-3703003179820

Cómo citar: Hayashi, E. A. P., \& Moriyama, J. S. (2019). Grupo de Apoyo Psicológico a Mujeres en Situación de Infertilidad. Psicologia: Ciência e Profissão, 39, 1-13. https://doi.org/10.1590/1982-3703003179820 